\title{
Amnésia Organizacional: um Estudo de Caso Sobre a Memória na Administração Pública Federal
}

\author{
Organizational Amnesia: a case study on memory in Brazilian Public Administration
}

\begin{abstract}
Aleksandra Pereira Santos
Doutoranda do Programa de Pós-Graduação em Psicologia Social, do Trabalho e das Organizações da Universidade de Brasília - UnB.

E-mail: aleksandrapds@gmail.com
\end{abstract}

\begin{abstract}
Resumo
Compreender as características da memória na administração pública mostra-se relevante para o entendimento do papel e da atuação do Estado brasileiro. Este texto buscou tal compreensão, a partir de estudo de caso da memória organizacional no Ministério do Planejamento, Orçamento e Gestão. Para tanto, buscou-se um referencial teórico integrando as Ciências da Informação e Administração, uma vez que o tema abrange teorias de gestão do conhecimento e aprendizagem organizacional. A análise de documentos e as entrevistas foram as técnicas de coleta de dados utilizadas. Foram analisados os aspectos relativos à percepção dos dirigentes sobre os processos de retenção, recuperação e uso de informações e/ou conhecimentos, evidenciando-se as barreiras culturais e técnicas. Os resultados apontam para a percepção da memória organizacional enquanto processo implícito, natural, em permanente desenvolvimento, composta de repositórios múltiplos não integrados, cuja fonte principal é o indivíduo.
\end{abstract}

Palavras-chave: memória organizacional, gestão do conhecimento, aprendizagem organizacional, administração pública e amnésia organizacional

\begin{abstract}
Knowing characteristics of the public administration memory is relevant to understanding the role of the Brazilian state. This is a case study on organizational memory at the Ministry of Planning, Budget and Administration. The theoretical framework integrates Information and Management Science, since the theme holds up Knowledge Management and Learning Organization theories. Documental analysis and interviews were techniques for data collection. Features related to the perception of management about processes of information and/or knowledge retention, recovery and use were analyzed. Cultural and technical barriers were revealed. The results pointed out to the perception of organizational memory as an implicit and natural process, in permanent development. This memory is composed by multiple and unintegrated repositories, which main source is the individual.
\end{abstract}

Keywords: Organizational Memory, Learning Organization, Knowledge Management, Public Administration and Organizational Amnesia

InCID: R. Ci. Inf. e Doc., Ribeirão Preto, v. 3, n.1, p. 36-56, jan./jun. 2012. 


\section{Introdução}

O advento da Sociedade da Informação estabeleceu novos paradigmas na relação entre o homem e as organizações. Nesse contexto, a informação e o conhecimento tornaram-se recursos transformadores nas organizações. Diferentes abordagens surgem sobre a gestão desses recursos. A maior parte delas tem como foco a descrição ou a prescrição de formas de criação, armazenagem e reutilização da informação e do conhecimento organizacional (CHOO, 2003; DAVENPORT; PRUSAK, 1999; NONAKA; TAKEUCHI, 1997). Especificamente sobre a retenção, recuperação e uso da informação e do conhecimento apresenta-se o conceito de memória organizacional (ALMEIDA, 2006; BANNON; KUUTTI, 1996; CAVALCANTE, 2005; CONKLIN, 2001; EBBERS E WIJNBERG, 2009; MORRISON; WEISER, 1996; STEIN, 1995).

Memória organizacional é, portanto, um conceito metafórico, que pressupõe a capacidade das organizações lembrarem de forma semelhante ao homem e indica a necessidade de identificar mecanismos capazes de gerar conhecimento e retê-lo. $\mathrm{O}$ conceito também está relacionado à memória declarativa, ou seja, aquela relacionada aos fatos e eventos com implicação direta nos modelos de aprendizagem e conhecimento organizacionais cujas abordagens são multidisciplinares e abrangem especialmente as áreas relacionadas à Psicologia, Administração, Ciência da Computação e Ciência da Informação (ALMEIDA, 2006).

No caso das organizações públicas brasileiras percebe-se que o conhecimento de práticas e processos pertence aos indivíduos, o que caracteriza um dos grandes dilemas das organizações: as pessoas tornaram-se as únicas "proprietárias" do conhecimento. É possível notar que o compartilhamento de experiências, sucessos, fracassos ocorre por meio de laços pessoais e não alcança as organizações (SANTOS, 2006).

Não existem indicadores efetivos da dimensão das práticas supracitadas, nem mesmo mensuração do impacto de ações relativas ao gerenciamento da informação e do conhecimento nos órgãos públicos, o que justifica o caráter exploratório da pesquisa e remete ao seu principal objetivo: apresentar fatores que podem estar associados aos processos de retenção, recuperação e uso de informações e conhecimentos passados nas organizações publicas. Para além do objetivo inicial, faz-se necessário conhecer os mecanismos de recuperação de informações ou conhecimentos que remetam a experiências vividas pela organização ou por seus membros e as 
ações que podem ser desenvolvidas com o objetivo de otimizar as práticas de armazenamento, recuperação e uso de informações e conhecimentos organizacionais.

Apresentar os processos de construção da memória organizacional de forma análoga aos processos concernentes à formação da memória individual remete à análise de um conceito fundamental para a compreensão e constituição do termo: a noção de aprendizagem, nos níveis individual e organizacional. Portanto, para a compreensão da memória organizacional e dos pressupostos construídos para sua verificação, são apresentados a seguir seus componentes basilares: gestão do conhecimento e aprendizagem organizacional.

\section{Gestão do Conhecimento}

As abordagens sobre gestão do conhecimento passam, inicialmente, pela distinção clássica entre dado, informação e conhecimento. Embora não exista um consenso quanto à diferenciação ou a definição entre esses três conceitos, conforme explica Tuomi (1999 ${ }^{1}$ apud SILVA, 2004), eles são geralmente apresentados de forma hierárquica. Dados são simples fatos que se combinados em uma estrutura compreensível se tornam informação e a informação, ao ser apresentada em um contexto e utilizada para fazer previsões ou atuar na tomada de decisão, torna-se conhecimento. Desta forma, cada elemento torna-se pré-requisito para a existência do outro.

Moresi (2001) apresenta uma classificação do conhecimento em formal e tácito ou informal. O conhecimento formal, segundo o autor, é concreto e está materializado nos livros, manuais, documentos, periódicos, base de dados, repositórios, além de outros meios. O conhecimento informal, por sua vez, caracteriza-se por ideias, fatos, suposições, decisões e questões, conjecturas e pontos de vista. Esse conhecimento é gerado e utilizado no processo de

produção do conhecimento formal sendo mais volátil em termos de coleta, estruturação e utilização pela organização.

\footnotetext{
${ }^{1}$ TUOMI, I. Data is more than knowledge: implications of the reversed knowledge hierarchy for knowledge management and organization memory. Journal of Management Information Systems, v. 16, n. 3, p. 103-117, Winter 1999.
}

InCID: R. Ci. Inf. e Doc., Ribeirão Preto, v. 3, n.1, p. 36-56, jan./jun. 2012. 
No que se refere a gestão do conhecimento, o conceito mais clássico é apresentado por Nonaka e Takeuchi (1997). Os autores estabelecem a distinção entre conhecimento formal ou explícito e informal ou tácito, distinguindo quatro processos de conversão do conhecimento: externalização, combinação, internalização e socialização que surgem da interação entre o conhecimento formal e informal e entre o conhecimento individual e organizacional.

A variedade de conceitos e a recente abordagem sobre gestão do conhecimento indicam um longo caminho a percorrer em termos de definição e mensuração de seu objeto de estudo: os mecanismos de criação, desenvolvimento e compartilhamento de conhecimento nas organizações. Stollenwerk (2001) defende que as diferentes abordagens em gestão do conhecimento têm como características comuns a descrição, a prescrição e o estudo de casos isolados.

Campos (2003) agrega as principais ideias a respeito de gestão do conhecimento em quatro vertentes:

a) vertente americana que, segundo o autor, tem como foco as ações gerenciais e a tecnologia para a disseminação do conhecimento (DAVENPORT; PRUSAK, 1999; WIIG, 1999);

b) vertente japonesa, cujas teorias estão centradas nos processos de criação do conhecimento e nos seus processos de conversão (NONAKA; TAKEUCHI, 1997);

c) vertente europeia, cujo objetivo principal é a medida dos ativos intangíveis da organização, ou seja, o seu capital intelectual (EDVISSON; MALONE, 1998); e

d) vertente brasileira, cujo foco está na interação homem e conhecimento, no processo de conversão do conhecimento para um crescimento organizacional sustentado e no conhecimento como fonte de vantagem competitiva (STOLLENWERK, 2001; MORESI, 2001).

O tema gestão do conhecimento e as decorrências implícitas ou explícitas de sua adoção na administração pública brasileira têm percorrido segmentos específicos do governo brasileiro há, pelo menos, uma década (SANTOS, 2006). Os principais obstáculos apontados para a implementação de projetos de gestão do conhecimento: inexistência de indicadores, falta de tempo ou de recursos para compartilhar conhecimento na rotina diária, baixa compreensão sobre 
o escopo da gestão do conhecimento na organização, dificuldade para capturar o conhecimento não documentado, falta de incentivos para compartilhar conhecimento, resistência de certos grupos de funcionários, cultura organizacional resistente a mudanças, deficiência de capacitação do pessoal, falhas de comunicação, pouco investimento em tecnologias voltadas para facilitação do aprendizado e colaboração, falta de comprometimento dos dirigentes, receio de que outros órgãos ou o público em geral possam ter acesso a informações sigilosas ou confidenciais e deficiências na infraestrutura computacional, redes, servidores, dentre outros. (BATISTA et al., 2005)

Desta forma, percebe-se que, apesar da importância crescente do conhecimento na sociedade, o termo gestão do conhecimento é ainda difícil de ser compreendido e apreendido nos órgãos da administração pública direta.

Do cenário marcado pela dinâmica do conhecimento, fator intangível e que alavanca os resultados organizacionais, surge a necessidade de apresentação do processo de aprendizagem em seus múltiplos níveis: individuais, organizacionais e grupais.

\section{Aprendizagem Organizacional}

A aprendizagem é um processo psicológico individual, caracterizado pela mudança relativamente permanente do comportamento a partir da interação com o contexto (ABBAD; BORGES-ANDRADE, 2004). De forma análoga aos processos de aprendizagem e para fazer referência metafórica ao processos que ocorrem no âmbito das equipes e da organização, ganha força, a partir da década de 80 , os estudos sobre aprendizagem organizacional. Tais estudos se desenvolveram em duas dimensões:

a) aprendizagem organizacional: representada pelos pesquisadores acadêmicos, cujo foco está no desenvolvimento de teorias a partir de pesquisas e investigações; e

b) organizações que aprendem: desenvolvida por consultores e pesquisadores orientados para a mudança organizacional, cujo objeto está na replicação de práticas bemsucedidas, orientando as organizações no que devem fazer para aprender. (ARGYRIS; SCHÖN, 1974)

InCID: R. Ci. Inf. e Doc., Ribeirão Preto, v. 3, n.1, p. 36-56, jan./jun. 2012. 
O sujeito da aprendizagem organizacional é ponto de tensão e conflito entre os pesquisadores. Uma visão mais crítica nega a aprendizagem no nível organizacional e afirma que a capacidade de aprender é exclusiva do homem. Considera-se, portanto, que é o indivíduo quem age e aprende no âmbito da estrutura organizacional, criando meios para a transformação da mesma (DODGSON, 1993).

Outra vertente enfatiza a aprendizagem organizacional como maior que a soma dos aprendizados individuais uma vez que a organização aprende independentemente da ação de um único indivíduo. Assim, a expressão aprendizagem organizacional passa a ser usada de forma metafórica e significa que o fenômeno da aprendizagem só pode ser compreendido a partir dos atores organizacionais (DOVING, 1996). Argyris e Schön (1996) registram que, se as organizações são coletividades formadas por indivíduos, as organizações aprendem tanto quando seus membros - ou parte deles - aprendem. Entretanto, esse aprendizado pode não ser proporcional, ou seja, a aprendizagem organizacional pode ser maior ou menor que a soma da aprendizagem individual dos membros da organização.

Considera-se, portanto, a aprendizagem organizacional como um fenômeno multinível, isto é, atua no nível do indivíduo, grupo e organização (CROSSAN; LANE; WHITE, 1999), tendo limitações decorrentes dos fatores estruturais encontrados (HUYSMAN, 2001). Para compreender como a aprendizagem, que ocorre no nível individual, pode produzir efeitos nos grupos e nas organizações é necessário utilizar o conceito de transferência entendida como a ocorrência de mudanças no indivíduo em situações distintas daquelas em que ocorreu a aquisição do conhecimento (PANTOJA; BORGES-ANDRADE, 2004).

Crossan, Lane e White 1999) identificam quatro etapas de aprendizagem integradas e analisadas em três níveis distintos: indivíduos, grupos e organizações: a) intuição, reconhecimento de novos padrões ou possibilidades com base em experiências prévias, imagens e metáforas; b) interpretação, compartilhamento nos grupos, significa dividir intuições, mediante conversações, metáforas e imagens; c) integração, ações coletivas do grupo, compartilhando interpretações ou compreensões em mapas cognitivos expressos através da linguagem e de maneira coordenada; e d) institucionalização, introdução de novas ações e interpretações nas rotinas, nas regras, nos sistemas de informação, na estratégia e na estrutura da organização. Zietsma et al. (2002) acrescentam, ainda, duas outras etapas de aprendizagem organizacional. São 
elas: a) captação, processo de busca das informações no ambiente; e b) experimentação, ocorre quando os indivíduos e grupos fazem experiências e os resultados de suas ações agregam substância às suas interpretações cognitivas.

De acordo com esse modelo, as etapas de intuição e captação ocorrem no nível individual; a interpretação ocorre tanto no nível individual, quanto no nível de grupo; a etapa de experimentação no nível de grupo; a integração ocorre no nível de grupo e da organização e a institucionalização ocorre exclusivamente no nível da organização (CROSSAN; LANE; WHITE, 1999; ZIETSMA et al.; 2002). A retroalimentação, por sua vez, consiste na aprendizagem que já

foi institucionalizada e afeta indivíduos e grupos (CROSSAN; LANE; WHITE, 1999). O produto desse processo de aprendizagem assume várias formas: interpretações de experiências passadas de sucesso ou fracasso; inferências sobre as conexões causais entre as ações e resultados e suas implicações para as ações futuras; descrições do ambiente organizacional em mudança e as demandas quanto ao desempenho futuro; análise dos limites e potencialidades das estratégicas, estruturas, técnicas e sistemas informacionais e sistemas de incentivo alternativos; descrição de visões e interesses conflitantes que surgem na organização sob condições complexas e incertas; imagens de realizações futuras e invenção de meios de atingi-los.

\section{Memória Organizacional}

Os primeiros estudos sobre memória se originaram na filosofia com Aristóteles e apenas com o desenvolvimento da psicologia, a memória - bem como a aprendizagem - passou a ser estudada a partir de métodos científicos (ALMEIDA, 2006). Assim, a memória integra-se ao grupo dos processos cognitivos que transformam, reduzem, elaboram, estocam, evocam e usam informações sensoriais. Ainda, supõe a mediação e o controle pela realidade (PENNA,1980).

Três grandes distinções sobre a memória são realizadas pela psicologia cognitiva. A primeira relaciona-se aos estágios da memória: codificação, armazenamento e recuperação; a segunda, diz respeito as diferentes memórias para armazenamento das informações por períodos longos e curtos; e a terceira à distinção sobre diferentes memórias utilizadas para armazenar diferentes tipos de informação (ATKINSON et al., 2002).

InCID: R. Ci. Inf. e Doc., Ribeirão Preto, v. 3, n.1, p. 36-56, jan./jun. 2012. 
Entre os modelos explicativos sobre a memória, o mais investigado é a relação entre a memória de curta e a de longa duração. A memória de curto prazo, ou de trabalho, é usada, por exemplo, quando memoriza-se um número de telefone apenas por tempo suficiente para descartálo. É caracterizada pela baixa retenção da informação e tem como papel fundamental determinar se a informação é útil e deve ser armazenada, se existem informações semelhantes e se a informação deve ser descartada quando já existe ou não possui utilidade. A memória de longo prazo ou referencial, por sua vez, possui um processo de formação de arquivo e consolidação, e pode durar de minutos ou horas a meses e décadas (ALMEIDA, 2006).

Além das abordagens individuais relacionadas à memória, há a noção de que o termo precisa ser entendido, como um fenômeno social, construído de forma coletiva e submetido às flutuações, transformações e mudanças constantes (HALBWACHS apud POLLAK, 1992).

Ainda no que se refere à memória, Cavalcante (2005) afirma tratar-se de uma construção inacabada. Para a autora, são as condições de inserção social do indivíduo que definem suas leituras e percepções, auxiliando-o na construção de suas experiências. Cavalcante (2005) também questiona como funcionariam as sociedades se as experiências vividas fossem ignoradas na construção do conhecimento, retomando a noção de memória que ultrapassa os suportes informacionais e os documentos materializados e se processa, primeiramente, nos indivíduos.

De forma análoga ao conceito de aprendizagem organizacional, o conceito de memória organizacional é utilizado em sentido metafórico, no intuito de explicar processos e práticas organizacionais para codificação, armazenamento e recuperação de informações e/ou conhecimentos. Suas abordagens são variadas e cada uma enfatiza um aspecto relevante e particular, inexistindo uma teoria que explique o assunto de forma abrangente. Assim, as pesquisas que abordam o tema atuam entre os fatores concretos - sistemas, banco de dados, bases de conhecimento, documentos, dentre outros - e fatores abstratos, como por exemplo: teorias, modelos explicativos, esquemas conceituais e cognitivos (ALMEIDA, 2006).

$\mathrm{Na}$ literatura dos estudos organizacionais e administrativos é possível encontrar pelo menos duas visões distintas relacionadas à memória organizacional (COOK; YANOW, $1993^{2}$ apud BANNON; KUUTTI 1996). A primeira visão tem como foco as capacidades cognitivas

\footnotetext{
${ }^{2}$ CONKLIN, J. ; YOURDON, E. Groupware for the new organization. American Programmer, Sept. 1993. p. 3-8. InCID: R. Ci. Inf. e Doc., Ribeirão Preto, v. 3, n.1, p. 36-56, jan./jun. 2012.
} 
individuais. Tais estudos vêm aprendizagem e memória organizacionais como estados já definidos. A segunda visão defende que a memória organizacional é uma forma de propriedade cognitiva de uma entidade coletiva organizacional e que em si mesma pode ser vista como aprendizagem e memorização. As duas visões sobre a memória organizacional são denominadas memória organizacional de expectativa e memória organizacional de procedimentos. A primeira como uma pré-condição para a segunda (EBBERS; WIJNBERG, 2009).

Além das abordagens cujo foco remete ao aprendizado organizacional e aos processos cognitivos individuais, outra vertente apresenta o enfoque tecnológico aos estudos sobre memória organizacional. Holsapple ( $1987^{3}$ apud BANNON; KUUTTI, 1996) defende que as tecnologias de informação surgem para garantir a integridade do conhecimento compartilhado, apresentando restrições da segurança e fornecendo velocidades de acesso. Em um posicionamento mais radical a respeito dos suportes tecnológicos nas estruturas de memória organizacional, Huber $\left(1990^{4}\right.$ apud ALMEIDA, 2006) aponta o componente humano como o componente falível.

Ao abordar a manutenção dos conteúdos armazenados, Stein (1995) aponta alguns fatores para a perda do conhecimento organizacional: destruição de registros físicos, rotatividade de pessoal e dificuldade de manter os padrões de interação. Por fim, quanto ao processo de recuperação o autor argumenta que ao não utilizar o conhecimento disponível (seja por razões políticas ou técnicas) a organização desperdiça recurso. Assim, a existência de barreiras tecnológicas, culturais e políticas para o desenvolvimento de mecanismos capazes de capturar o conhecimento informal tornando-o explícito, são relevantes para análise da memória organizacional.

Entre as barreiras apontadas anteriormente destacam-se: a existência do conhecimento informal e a extrema dificuldade na sua captura e transformação; a prática na preservação de documentos, cujo foco está no armazenamento, sem preservação do contexto no qual o conhecimento foi produzido ou utilizado; a perda de relevância de determinado conhecimento após seu uso; ou o incentivo que as organizações têm para apagar documentos capazes de prejudicar sua atuação (COKLIN, 2001). Caracteriza-se, assim o fenômeno de esquecimento

\footnotetext{
${ }^{3}$ HOLSAPPLE, C. W.; WHINSTON, A. B. Knowledge Based Organizations. TheInformation, v. 5, p. 77-90, 1987. ${ }^{4}$ HUBER, G.P. A Theory Of The Effects Of Advanced Information Technologies. The Academy of Management Review, v. 15, n. 1, p.47-71, 1990. Disponível em:

<http://proquest.umi.com/pqdlink?RQT=572\&TS=1123286950\&clientId=49682\&VType=PQD\&VName=PQD\&VI nst=PROD\&PMID=19602\&PCID=5668\&SrtM=0\&SrchMode=3\&aid=11>. Acesso em: 11 jan. 2005.
}

InCID: R. Ci. Inf. e Doc., Ribeirão Preto, v. 3, n.1, p. 36-56, jan./jun. 2012. 
organizacional, explicável por alguns fenômenos: quando os membros da organização produzem conhecimento, mas este não é transferido para a organização ou quando as informações não possuem manutenção, conservação efetivas ou repositórios adequados. O esquecimento ou falta de memória organizacional é dicotômico e por isso pode ser prejudicial à organização, principalmente quando ocorrem repetições de processos, projetos, ações ou até mesmo fracassos (ALMEIDA, 2006).

Para a abordagem de um tema tão emergente quanto complexo - memória organizacional - inserido em um contexto igualmente peculiar - administração pública brasileira - no qual a abordagem sobre as práticas de gestão do conhecimento ainda é incipiente, o desenho metodológico qualitativo, exploratório e intensivo, cujo foco se dá em um determinado setor da administração pública, mostrou-se adequado e relevante para o entendimento do fenômeno, bem como coerente aos propósitos de investigação.

\section{Método}

O estudo de caso tomou como unidade de análise o Ministério do Planejamento, Orçamento e Gestão (MP) cuja missão é promover o planejamento participativo e a melhoria da gestão pública para o desenvolvimento sustentável e socialmente includente do pais.

Diante da amplitude de atuação do MP, o estudo teve como foco as competências relativas à gestão, por meio das quais o Ministério executa a função de formulador de políticas nos demais órgãos da administração pública federal. Considerou-se, portanto, as atribuições de: a) coordenação e gestão dos sistemas de planejamento e orçamento federal, pessoal civil, administração de recursos da informação e informática e serviços gerais; b) ações de organização e modernização administrativa do Governo Federal; e c) formulação de diretrizes para modernização do Estado. Tais competências são exercidas por cinco unidades específic as que compõem a estrutura do Ministério e se constituíram amostra da presente pesquisa: Secretaria de Planejamento e Investimentos Estratégicos (SPI), Secretaria de Orçamento Federal (SOF), Secretaria de Gestão (Seges), Secretaria de Logística e Tecnologia da Informação (SLTI) e Secretaria de Recursos Humanos (SRH).

InCID: R. Ci. Inf. e Doc., Ribeirão Preto, v. 3, n.1, p. 36-56, jan./jun. 2012. 


\section{Instrumentos e Procedimentos}

Foram utilizadas a análise de documentos e a entrevista. Uma vez que o termo memória organizacional apresenta-se de forma complexa e pouco delimitada; e considerando os objetivos da pesquisa, foi analisado como os dirigentes máximos de cada unidade recuperavam e utilizavam informações e conhecimentos necessários às atuações de suas Secretarias, bem como qual o entendimento frente ao uso e sistematização da memória organizacional. As entrevistas estruturadas foram realizadas com o dirigente máximo de cada Secretaria cujas atribuições compreendem: planejamento, direção, coordenação, orientação, acompanhamento e avaliação das atividades das unidades que integram suas respectivas áreas. Foi realizada, ainda, uma entrevista semi-estruturada com a titular da Coordenação de Documentação e Informação (Codin), unidade organizacional da Subsecretaria de Planejamento, Orçamento e Administração (SPOA) que, por sua vez, está vinculada à Secretaria Executivo do Ministério) e tem como principal atribuição fornecer suporte documental e informacional às demais áreas do Ministério do Planejamento, Orçamento e Gestão.

As entrevistas estruturadas foram construídas com o objetivo de investigar os processos de memória organizacional: codificação, armazenamento e recuperação de informações ou conhecimentos organizacionais, para em seguida investigar as barreiras - culturais e técnicas existentes. Obedeceram, portanto, à seguinte estrutura: fontes e repositórios de informação, processos de recuperação da informação e/ou conhecimentos, barreiras à recuperação e importância da memória organizacional para a condução de políticas. São exemplos de questões: "quais as principais fontes de informação utilizadas na organização?" e "quais os repositórios informacionais existentes na organização e que permitem a recuperação de informações e/ou conhecimentos passados?

A entrevista semi-estruturada buscou investigar a atuação da Codin enquanto órgão de suporte informacional às demais unidades do Ministério. O guia da entrevista, composto principalmente de questões abertas e confrontativas (FLICK, 2004), debruçou-se sobre a estrutura organizacional da unidade, seus principais projetos, fragilidades e mecanismos de atuação com as demais unidades do Ministério.

InCID: R. Ci. Inf. e Doc., Ribeirão Preto, v. 3, n.1, p. 36-56, jan./jun. 2012. 
As entrevistas estruturadas, no total de seis foram realizadas em maio de 2007, com duração aproximada de 50 minutos. A entrevista semi-estruturada foi realizada nesta época e possuiu duração aproximada de uma hora.

\section{Análise de Dados}

Os dados coletados foram analisados a partir de duas perspectivas: a análise global de conteúdo e a análise qualitativa de conteúdo (FLICK, 2004). Assim, buscou-se inicialmente, a partir da abreviação da análise de conteúdo construir a interpretação dedutiva dos dados, considerando os pressupostos e variáveis apresentadas como categorias de conteúdo.

A partir dos objetivos de pesquisa e considerando o referencial teórico apresentado foram construídos os seguintes pressupostos: a) os mecanismos de retenção de informações e conhecimentos necessários para a ação ou tomada de decisão não estão estruturados; ocorrem, na maioria das vezes, em nível individual e com pouco uso da tecnologia; b) a memória organizacional não é percebida como ferramenta para a ação organizacional e para a tomada de decisão, desta forma não há um projeto para retenção, recuperação e utilização de informações ou conhecimentos passados; e c) os fatores determinantes da memória organizacional são os indivíduos e os grupos; e, em baixa escala, as tarefas, o contexto organizacional e a tecnologia.

Foram estabelecidas, como variáveis de pesquisa: a) práticas de retenção, recuperação e uso do conhecimento e/ou informações passados; b) influência da memória individual nos processos de gestão; c) qualidade da informação e/ou do conhecimento recuperado; d) utilização de ferramentas ou sistemas para recuperação e uso do conhecimento e/ou informações passados; e) condições necessárias à implantação de práticas para retenção, recuperação e uso do conhecimento e/ou informações passados; f) legado institucional; e g) barreiras culturais e técnicas à recuperação e uso da informação e/ou conhecimento passados

InCID: R. Ci. Inf. e Doc., Ribeirão Preto, v. 3, n.1, p. 36-56, jan./jun. 2012. 


\section{Resultados}

Os resultados serão apresentados e discutidos a partir das variáveis construídas para o estudo proposto anteriormente descritas

No que se refere as práticas de retenção, recuperação e uso do conhecimento e/ou informações passados; experiência e conhecimentos próprios, assim como experiência e conhecimentos de grupos externos, foram as práticas mais apontadas. Ainda, a percepção do contexto e ambiente organizacional surgiu como fonte para recuperação de informação e conhecimento

Nota-se a predominância de um mecanismo de memória organizacional apresentado por Walsh e Ungson (1991 ${ }^{5}$ apud ALMEIDA, 2006), quer seja, o indivíduo, seja por meio da consulta aos membros da organização que mantém registros e arquivos como auxiliares de memória, seja consulta aos membros externos capazes de fornecer subsídios aos processos de tomada de decisão. A análise desta variável também é mensurada pelas ações de retenção e recuperação desenvolvidas na organização, bem como pelas práticas de estímulo ao aprendizado e à construção de repositórios de informação. Tais medidas foram identificadas, a partir das entrevistas realizadas, em quatro das cinco unidades analisadas, ainda que em estágios diferenciados. Foi possível perceber, ainda, que a implantação de tais ações e/ou práticas está relacionada à percepção de sua importância nos processos organizacionais e ao estilo de liderança de cada dirigente (ALVARENGA NETO; BARBOSA, 2005; CAMPOS, 2003).

Quanto à influência da memória individual nos processos de gestão organizacional, para todos os gestores entrevistados, a memória individual é relevante aos processos de gestão das suas organizações. Desta forma, há a percepção unânime quanto à necessidade de construção do conhecimento organizacional, a partir da conversão do conhecimento tácito ou informal, assim como para a premência de ações que estimulem esse processo (NONAKA; TAKEUCHI, 1997). Pode-se perceber, portanto, a existência de fatores que minimizam a dependência da memória individual nos processos de gestão organizacional: a) o perfil dos servidores cuja qualificação

\footnotetext{
${ }^{5}$ WALSH, J.P.; UNGSON, G.R. Organizational memory. The Academy of Management Review. v. 16, n. 1, p. 5791, 1991. Disponível em:

<http://proquest.umi.com/pqdlink?PMID=19602\&TS=1123285174\&SrchMode=3\&SrtM=0\&PCID=5672\&VType= PQD\&VInst=PROD\&aid=4\&clientId=49682\&RQT=572\&VName=PQD\&firstIndex=10>. Acesso em: 12 mar. 2005.
}

InCID: R. Ci. Inf. e Doc., Ribeirão Preto, v. 3, n.1, p. 36-56, jan./jun. 2012. 
adequada indica maior capacidade para disponibilizar e compartilhar informação ou conhecimento; e b) ações gerenciais decorrentes do perfil do dirigente que se refletem em estímulo ao compartilhamento da informação e/ou conhecimento.

No que se refere à qualidade da informação e/ou do conhecimento recuperado, os entrevistados consideram as informações e os conhecimentos recuperados satisfatórios em temos de conteúdo, volume e credibilidade. Entretanto, enfatizam que nem sempre as informações e/ou conhecimentos passados são acessíveis ou facilmente recuperáveis, o que, algumas vezes, gera problemas no órgão. Percebe-se, assim, uma preocupação na sistematização e registro de informações e/ou conhecimentos para uso futuro, ainda que de uma forma incipiente, apontada por dois dos cinco entrevistados.

Para a variável utilização de ferramentas ou sistemas para a recuperação e uso do conhecimento e/u informações passadas, os dirigentes foram unânimes em apontar o uso de repositórios individuais, de grupos ou de equipes como instrumentos de acesso às informações e/ou aos conhecimentos passados. Entretanto, tal instrumento é utilizado de forma menos intensa em duas das cinco secretarias analisadas. Tal intensidade ocorre em função da existência de outras ferramentas para acesso à informação e/ou conhecimento. Percebe-se, portanto, duas situações distintas: a) o uso de outros instrumentos de acesso à informação e/ou conhecimento passados e dos repositórios individuais, assim como de outros instrumentos. Nesse caso, também foram apontados: portais, comunidades de práticas, fóruns ou listas de discussão e sistemas específicos de cada órgão; b) o uso de repositórios individuais, de grupos ou equipes de forma intensa, quando não se utiliza outras ferramentas para acesso à informação ou ao conhecimento passados.

Quanto às condições necessárias à implantação de práticas para retenção, recuperação e uso do conhecimento e/ou informações passados, os entrevistados defendem a existência de fatores culturais, políticos e institucionais na implantação de práticas relativas à memória organizacional. De maneira geral, o fator cultural mostrou-se com influência significativa em todas as organizações analisadas; em seguida, o fator político, e por último, o fator institucional.

A abordagem sobre o legado de cada órgão pesquisado foi feita a partir do relato da trajetória do dirigente, das suas experiências, do contato prévio com os temas específicos da correspondente Secretaria e das suas primeiras impressões sobre os projetos e ações InCID: R. Ci. Inf. e Doc., Ribeirão Preto, v. 3, n.1, p. 36-56, jan./jun. 2012. 
desenvolvidos. Convém destacar que este tópico ensejou também a análise da memória produzida na gestão dos entrevistados para seus respectivos sucessores. Verificou-se, portanto, que as secretarias analisadas e seus dirigentes possuem formas distintas de armazenar informações e conhecimentos considerados relevantes para a condução de suas atividades. De uma maneira geral, foram percebidas quatro situações: a) o dirigente possuía experiência prévia nos temas de atuação do órgão, conhecendo ações e projetos desenvolvidos quando da sua nomeação; além disso, existiam práticas de retenção e recuperação de informações e conhecimentos passados; b) o dirigente possuía experiência prévia nos temas de atuação do órgão, conhecendo ações e projetos desenvolvidos quando da sua nomeação; entretanto, não existiam práticas consolidadas de retenção e recuperação de informações e conhecimentos passados; c) o dirigente não possuía experiência prévia sobre os temas de atuação do órgão, com pouco conhecimento de ações e projetos em desenvolvimento; por outro lado, existiam práticas de retenção e recuperação de informações e conhecimentos passados; e d) o dirigente não possuía experiência prévia sobre os temas de atuação do órgão, com pouco conhecimento de ações e projetos em desenvolvimento, acrescentando-se a ausência de práticas consolidadas de retenção e recuperação de informações e conhecimentos.

De acordo com o exposto pelos gestores entrevistados, foi possível verificar a existência em maior ou menor grau das barreiras culturais e técnicas à memória organizacional apresentadas por Conklin (2001). A ênfase nos resultados foi apresentada por todos os dirigentes como barreira aos processos de recuperação e utilização de informações e/ou conhecimentos passados. Outra barreira identificada por todos os gestores entrevistados, ainda que sua relevância seja diferenciada nas unidades, é o medo em compartilhar informação ou conhecimento e, portanto, certa resistência de pessoas ou grupos ao processo de compartilhamento. A falta de prioridade ou de incentivos organizacionais para as práticas de gestão da informação e/ou conhecimento foi apontada, por todos os gestores, como barreira à recuperação e uso da informação e/ou conhecimento. Contudo há tentativa setorial de minimizar ou superar essa barreira.

No que se refere às barreiras técnicas, foi também unânime a deficiência de pessoas para a execução das ações necessárias à retenção e uso de informação e/ou conhecimento. Ainda quanto às barreiras técnicas apresentadas, as deficiências em comunicação e em gestão de pessoas 
aportam como empecilhos à armazenagem e recuperação da informação para quatro dos cinco entrevistados.

Quanto à reestruturação organizacional, os gestores não foram unânimes em percebê-la como barreira à memória organizacional. É possível perceber três posicionamentos distintos a respeito da reestruturação e sua influência nos processos de retenção e uso de informações e conhecimentos passados. O primeiro, se refere à ideia da reestruturação vista como oportunidade de reflexão sobre os processos ou sobre o próprio trabalho e, portanto, estimulo à sistematização dos conhecimentos e ao aproveitamento de experiência. O segundo, sustenta que a qualificação técnica da equipe e a existência de linhas de atuação mais permanentes impedem que, nos processos de reestruturação, a organização perca informações ou conhecimentos. Por fim, o último posicionamento firma-se na concepção de inovação e não aproveitamento de experiências anteriores, conforme defende Jardim (1995).

Ainda que todos os gestores entrevistados considerem a memória individual como relevante nos processos de gestão das organizações, a movimentação de pessoas não foi indicada como barreira significativa para os processos de memória. Isso porque, conforme os gestores entrevistados, tal movimentação não é intensa.

\section{Conclusão}

Ao tentar capturar o fenômeno memória organizacional, tendo o Ministério do Planejamento, Orçamento e Gestão como objeto de estudo, percebeu-se a complexidade e fragmentação do tema. Portanto, não é possível tratar de uma memória organizacional única, cujos repositórios podem ser previamente identificados e classificados, mas apontar para um processo inconsciente e sem uniformidade no qual algumas áreas ou sistemas de gestão vêm desenvolvendo práticas ou estimulando comportamentos capazes de minimizar a dependência individual nos processos de retenção, recuperação e uso de informações e/ou conhecimentos.

As práticas supracitadas não possuem caráter exclusivamente tecnológico, mas decorrem principalmente de um novo estilo de gestão, cujo foco está no compartilhamento de experiências individuais e grupais, bem como no resgate histórico da organização e do seu papel na sociedade como formas de criar um ambiente de trabalho amistoso aos seus membros.

InCID: R. Ci. Inf. e Doc., Ribeirão Preto, v. 3, n.1, p. 36-56, jan./jun. 2012. 
Há, assim, uma diferenciação significativa entre as unidades do Ministério quanto à capacidade de retenção, recuperação e uso de informações e/ou conhecimentos passados; e quanto à criação de um ambiente propício que estimule o uso de tais mecanismos. Constatou-se dois fatores determinantes da memória organizacional das unidades. O primeiro fator refere-se ao estilo de liderança, ou seja, às práticas emanadas da figura do dirigente. Nesse sentido, ainda que as unidades organizacionais tenham baixa capacidade de retenção, recuperação e uso de informações e/ou conhecimentos passados, o dirigente estimula o compartilhamento de conhecimento por meio do trabalho em equipe ou da gerência de projetos, o que minimiza a sujeição a memória de um indivíduo ou membro da equipe. O segundo fator está relacionado à profissionalização dos servidores da unidade que pode ser verificada no que diz respeito à escolaridade e principalmente à adequação entre as competências organizacionais e os cargos efetivos dos seus membros. Desta forma, a alta profissionalização da organização influencia na sua capacidade de retenção, recuperação e uso da informação e/ou conhecimentos passados.

Pode-se concluir que os mecanismos de retenção, recuperação e uso de informações e/ou conhecimentos nas unidades do MP são múltiplos e não integrados. Ainda que a tecnologia não seja percebida como barreira à memória organizacional, não se encontra compartilhada ou difundida em todas as unidades da organização. Boa parte de informações e conhecimentos recuperados pelos dirigentes provêm dos membros da organização ou de indivíduos a ela relacionados. Desta forma, a memória individual torna-se intrínseca aos processos de gestão organizacionais. A implantação de práticas setoriais, como o desenvolvimento de manuais; ou ainda, o estímulo ao uso de ferramentas tecnológicas, como portais e redes internas, indicam a redução do fator individual nos processos de memória, porém tais práticas ainda estão setorializadas.

Ainda que existam práticas setoriais de retenção, recuperação e uso de informações e/ou conhecimentos passados, elas não se inserem em um projeto deliberado e específico de memória organizacional. Da maneira geral, os processos de recuperação e uso de informação e/ou conhecimentos passados não são formalizados ou sistematizados, enfatizando que não há percepção explícita da memória organizacional como ferramenta para tomada de decisão.

A inexistência ou a fragilidade do legado institucional, ou seja, a precariedade dos processos de registro e retenção de ações, projetos e experiências de uma unidade transmitidas 
aos seus sucessores indica a forte dependência das fontes individuais para a recuperação de informações e/ou conhecimentos. Por outro lado, as interações sociais, ambientais, tecnológicas e estruturais que percorrem a organização, assim como as atividades desenvolvidas consubstanciam impressões pessoais e auxiliam nas decisões, embora não se caracterizem como determinantes do processo. Por fim, a utilização de ferramentas tecnológicas para acesso e recuperação de informações no nível gerencial é reduzida.

Quanto à reestruturação organizacional, ainda que seja recorrente, não produz alterações consideráveis nas competências das unidades. Desta forma, mantêm-se as principais atribuições e o acúmulo informacional sobre as mesmas. As principais razões para a "perda" da memória sofrida nas unidades seriam: a) ênfase nos resultados organizacionais e necessidade de dar respostas rápidas: impedem maior reflexão sobre os processos de retenção, recuperação e uso das informações e/ou conhecimentos produzidos, assim como o desenvolvimento de práticas capazes de otimizar esse processos; b) prioridade organizacional para o desenvolvimento de práticas de retenção e falta de incentivos para o compartilhamento de conhecimento: as práticas de gestão do conhecimento, incluindo, segundo os dirigentes entrevistados, não são percebidas como prioridade para as unidades do Ministério; c) necessidade de pessoas: por reconhecer a premência de mecanismos formais de memória organizacional e gestão do conhecimento, os gestores entrevistados apontam a necessidade de servidores hábeis na sistematização de informações e conhecimentos disponíveis nas unidades.

Existem limitações quanto ao tema e método de pesquisa: a) estar em fase de construção teórica e inicial verificação empírica nas organizações; e b) apresentar caráter exploratório, ainda que em análise de profundidade quanto ao caso investigado. Espera-se que os resultados desse estudo possam transcender ao caso e que os conhecimentos adquiridos possam ser relevantes para a compreensão da memória organizacional na administração pública brasileira e para os estudos teóricos e empíricos sobre o tema. Investigar a memória organizacional na administração pública permitiu a apresentação do "estado da arte" desse conceito e seu entendimento no setor público e, portanto, a reflexão sobre as técnicas ou modelos de gestão mais adequados ou mais convenientes a esse setor.

Por fim, é possível apontar para a fragilidade dos instrumentos de codificação, armazenagem e recuperação das informações na organização, aliados à dificuldade de captura e 
transformação dessas. Ainda, a existência de barreiras técnicas e culturais e a incapacidade de transferência dos conhecimentos individuais para a organização, permite diagnosticar, de forma metafórica à aprendizagem e à memória organizacionais, um caso de amnésia organizacional.

\section{Referências}

ABBAD, G. S.; BORGES-ANDRADE, J. E. Aprendizagem humana em organizações de trabalho. In: ZANELLI, J. C.; BORGES-ANDRADE, J. E.; BASTOS, A. V. B. (Org.). Psicologia, Organizações e Trabalho no Brasil. Porto Alegre: Artmed, 2004, p. 237-275.

ALMEIDA, M. B. Um modelo baseado em ontologias para a representação da memória organizacional. 2006. 321p. Tese (Doutorado em Ciência da Informação) - Programa de PósGraduação em Ciências da Informação, Escola de Ciências da Informação, Universidade Federal de Minas Gerais, Belo Horizonte, 2006.

ALVARENGA NETO, R. C.; BARBOSA, R. R. Gestão da informação e do conhecimento em organizações brasileiras: proposta de mapeamento conceitual integrativo. In: ENCONTRO NACIONAL DE PESQUISA EM CIÊNCIA DA INFORMAÇÃO, 6, 2005, Florianópolis. Anais... Florianópolis: ENANCIB, 2005. 1 CD.

ARGYRIS, C.; SCHÖN, D. Theory in practice: increasing professional effectiveness. San Francisco: Jossey-Bass, 1974.

Organizational learning II: theory, method and practice. Massachussets: AddisonWesley Publishing Company, 1996.

ATKINSON, R. L. et al. Introdução à psicolgia de Hilgard. 13. ed. Porto Alegre: Artmed, 2001.

BANNON, L. J.; KUUTTI, K. Shifting perspectives on organizational memory: from storage to active. In: ANNUAL HAWAII INTERNATIONAL CONFERENCE ON SYSTEM

SCIENCES, 1996, Hawaii. Proceedings... Disponível em:

<http://csdl2.computer.org/comp/proceedings/hicss/1996/7330/00/73300156.pdf>. Acesso em:12 mar. 2011.

BATISTA, F. F., et al. Gestão do conhecimento da administração pública. Ipea, Brasília: 2005. Disponível em: <http://www.ipea.gov.br/pub/td/2005/td_1095.pdf〉. Acesso em: 12 mar. 2011.

CAMPOS, M. M. Gestão do conhecimento organizacional da administração pública federal em Brasília: um estudo exploratório. 2003.126 f. Dissertação (Mestrado em Ciência da Informação) - Programa de Pós-Graduação em Ciências da Informação, Faculdade de Ciências da Informação, Universidade de Brasília, Brasília, 2003. 
CAVALCANTE, L. E. O movimento da memória: um desafio metodológico o campo informacional. In: ENCONTRO NACIONAL DE PESQUISA EM CIÊNCIA DA INFORMAÇÃO, 6., 2005, Florianópolis. Anais... Florianópolis: ENANCIB, 2005. 1 CD.

CHOO, C. W. A organização do conhecimento: como as organizações usam a informação para criar siginificado, construir conhecimento e tomar decisões. São Paulo: Senac, 2003.

CONKLIN, J. Designing organizational memory: preserving intellectual assets in a knowledge economy. Disponível em: 〈http://cognexus.org/dom.pdf〉. Acesso em: 10 mar. 2011.

CROSSAN, M. M.; LANE, H. W.; WHITE, R. E. An organizational learning framework: from intuition to institution. Academy of Management Review, v. 24, n. 3, 1999.

DAVENPORT, T. H; PRUSAK. L. Conhecimento empresarial. São Paulo: Publifolha, 1999.

DODGSON, M. Organizational learning: a review of some literatures. Organizations Studies. v. 14, n. 3, p. 375-394, 1993.

DOVING, E. The image of man: organizational action, competence and learning. London: Sage, 1996.

EBBERS, J. J.; WIJNBERG, N. M. Organizational memory: from expactations to procedural memory. British Journal of Management. v. 20, p. 478-490, 2009.

EDVINSSON, L.; MALONE, M. S. Capital intelectual: descobrindo o valor real de sua empresa pela identificação de seus valores internos. São Paulo: Makron Books, 1998.

FLICK, U. Uma introdução à pesquisa qualitativa. Porto Alegre: Bookman, 2004.

HUYSMAN, M. Contrabalançando tendenciosidades: uma revisão crítica da literatura sobre aprendizagem organizacional. In: ESTERBY-SMITH, M; BURGYONE J; ARAUJO, L. Aprendizagem organizacional e organização de aprendizagem: desenvolvimento na teoria e na prática. São Paulo: Atlas, 2001.

JARDIM, J. M. A invenção da memória dos arquivos públicos. Ciência da Informação, Brasília, v. 25, n. 2, 1995. Disponível em:

<http://www.ibict.br/cionline/viewarticle.php?id=480>. Acesso em: 12 mar. 2011.

MORESI, E. A. Inteligência organizacional: um referencial integrado. Ciência da Informação, Brasília, v. 30, n. 2, p. 35-46, mai./ago. 2001. Disponível em:

<http://www.scielo.br/pdf/ci/v30n2/6210.pdf>. Acesso em: 12 mar. 2011

MORRISON, J.; WEISER, M. A research framework for empirical studies in organizational memory. In: ANNUAL HAWAII INTERNATIONAL CONFERENCE ON SYSTEM

SCIENCES, 1996, Hawaii. Proceedings... Disponível em: 
<http://csdl2.computer.org/comp/proceedings/hicss/1996/7330/00/73300156.pdf>. Acesso em: 12 mar. 2011.

NONAKA, I.; TAKEUCHI H. Criação do conhecimento da empresa: como as empresas japonesas geraram a dinâmica da inovação. Rio de Janeiro: Campus, 1997.

PENNA, A. G. Aprendizado e motivação. Rio de Janeiro: Zahar, 1980.

PANTOJA, M. J.; BORGES-ANDRADE, J. E. Contribuições teóricas e metodológicas da abordagem multinível para o estudo da aprendizagem e sua transferência nas organizações.

Revista de Administração Contemporânea, v. 8, n .4, p. 115-138, out./dez. 2004. Disponível em: <http://www.anpad.org.br/rac/vol_08/dwn/rac-v8-n4-mjp.pdf>. Acesso em: 02 maio 2007.

POLLAK, M. Memória e identidade social. Estudos Históricos, Rio de Janeiro, v. 5, n. 10, p. 200-212, 1992

SANTOS, A. P. Gestão do conhecimento em organizações que aprendem: gestão de competências e retenção de talentos. In: CONGRESO INTERNACIONAL DEL CLAD SOBRE LA REFORMA DEL ESTADO Y DE LA ADMINISTRACIÓN PÚBLICA, 11., 2006, Guatemala. Anais... Guatemala: CLAD, 2006. 1 CD.

SILVA, S. L. Gestão do conhecimento: uma revisão crítica orientada pela abordagem da criação do conhecimento. Ciência da Informação, Brasília, v. 33, n. 2, p. 143-151, mai./ago. 2002.

STEIN, E. W. Organizational memory: review of concepts and recommendations for management. International Journal of Information Management, v. 15, n. 1, 1995.

STOLLENWERK, M. F. L. Gestão do conhecimento: conceitos e modelos. In: TARAPANOFF, K. (Org.). Inteligência organizacional e competitiva. Brasília: Editora Universidade de Brasília, 2001. p. 143-163.

WIIG, K. M. Comprehensive knowledge management foundations. Arlington: Knowledge Research Institute, 1999. Disponível em:

<http://www.krii.com/downloads/comprehensive_km.pdf.> Acesso em: 11 mar. 2011.

ZIETSMA, C. et al. The war of the woods: facilitators and impediments of organizational learning processes. British Journal of Management, v. 13, p. 61-74, 2002.

Artigo submetido em: 12 mar. 2011

Artigo aceito em: 20 abr. 2011 